\title{
Dialogia
}

\section{Sobre escolas, unidades de polícia pacificadora (UPPs) e desigualdades de oportunidades educacionais na cidade do Rio de Janeiro}

\author{
On schools, pacifying police units (UPPs) and inequalities of educational opportunities
}

in the city of Rio de Janeiro

\begin{abstract}
Robert Lee Segal
Doutor em Educação, pela Universidade Federal do Rio de Janeiro. Docente do curso de licenciatura a distância em Pedagogia da Universidade Federal do Estado do Rio de Janeiro, Rio de Janeiro - RJ, Brasil. robertsegal70@gmail.com
\end{abstract}

Resumo: O presente artigo tem como objetivo apresentar os dados de uma pesquisa longitudinal qualitativa sobre desigualdades de oportunidades educacionais de estudantes moradores de "favelas", na cidade do Rio de Janeiro, na região da "Grande Tijuca", com foco na questão das matrículas nas turmas de ensino fundamental das escolas públicas municipais, considerando a limitação de mobilidade imposta pela origem residencial desses mesmos estudantes e o "ethos guerreiro" como reflexo da atuação de grupos de narcotraficantes, a partir das percepções dos funcionários naqueles estabelecimentos de ensino, em contexto de atuação das Unidades de Polícia Pacificadora (UPPs), entre os anos de 2014 e 2019. Em relação às suas conclusões parciais, verifica-se que tais unidades policiais pouco ou nada modificaram o quadro de desigualdade de oportunidades educacionais, tendo em vista a persistência das chamadas "fronteiras invisíveis" entre as favelas e mesmo entre escolas públicas.

Palavras-chave: Escolas e Unidades de Polícia Pacificadora (UPPs). Desigualdades de oportunidades educacionais e favelas. Violência urbana e escolas.

Abstract: This article aims to show the data of a longitudinal qualitative research on inequalities of educational opportunities to students living in "favelas", in the city of Rio de Janeiro, in the area known as "Grande Tijuca", focusing on the issue of enrollment in classes of the elementary level of public schools, considering the limitation of mobility imposed by the residential origin of these same students and the "warrior ethos" as a reflection of the actions of drug dealers, based on the perceptions of the employees in those educational establishments, in the context of performance of the Pacifying Police Units (UPPs) between 2014 and 2019. In relation to their partial conclusions, it can be seen that these police units had little influence or has not changed at all in a context of inequality of educational opportunities, given the persistence of calls "invisible borders" between "favelas" and even between public schools.

Keywords: Inequality of educational opportunities and "favelas". Schools and Pacifying Police Units (UPPs). Urban violence and schools.

Dialogia, São Paulo, n. 32, p. 278-291, maio/ago. 2019 


\section{Introdução}

O presente artigo tem como objetivo apresentar os dados de uma pesquisa longitudinal qualitativa acerca das desigualdades de oportunidades educacionais de estudantes moradores de favela, na cidade do Rio de Janeiro, na região conhecida como "Grande Tijuca", que agrega bairros como Alto da Boa Vista, Andaraí, Grajaú, Maracanã, Praça da Bandeira, Tijuca e Vila Isabel, considerando, num contexto de atividade das Unidades de Polícia Pacificadora (UPPs).

No tocante às oportunidades educacionais, importa aqui considerar as possibilidades de escolha das escolas, por parte das famílias e a chance de seus filhos de frequentar tais estabelecimentos, tendo em vista o sistema de matrícula adotado pela Secretaria Municipal de Educação do Rio de Janeiro, da Pré-Escola e Ensino Fundamental ( $1^{\circ}$ ao $9^{\circ}$ ano), por intermédio de cadastramento prévio na própria rede municipal (BRUEL, 2014).

Entretanto, mesmo diante de uma aparente liberdade de escolha por parte das famílias, há uma série de fatores que parecem dificultar o acesso de crianças e adolescentes, sob suas responsabilidades, em algumas escolas municipais do Rio de Janeiro, tais como a grande demanda das famílias sobre algumas escolas, cujas reputações são prestigiosas, causando a escassez de vagas nestas mesmas instituições (COSTA; KOSLINSKI, 2011; ZUCCARELLI; CID, 2010) e a questão da proximidade entre lares e escolas, que definem estratégias de escolha de determinados estabelecimentos em detrimento de outros (COSTA, KOSLINSKI; 2011; COSTA; PRADO; ROSISTOLATO, 2013).

Isto importa a um estudo, sobretudo, quando se está diante de uma dualidade entre "escolas do asfalto" e "escolas de favela", que, na prática, engendra uma restrição de oportunidades educacionais de crianças e adolescentes residentes em favelas em escolas situadas fora desses territórios, mantendo-as numa situação de isolamento social, reforçando segregações socioeconômicas (BRITO; COSTA, 2010; CHRISTÓVÃO; SANTOS, 2010; SMALL, 2004).

Dessa maneira, a questão concerne à geografia de oportunidades educacionais. Em que pese uma grande geografia objetiva de oportunidades educacionais, como na cidade do Rio de Janeiro, tendo em vista um grande universo de escolas municipais postas à disposição dos interessados, a geografia subjetiva de oportunidades se reduz, à medida que as famílias percebem que o acesso a essas mesmas escolas não é facilitada (FLORES, 2008).

Partindo-se do pressuposto que existiriam desigualdades de oportunidades educacionais decorrentes dos fatores até aqui apontados, também tem interessado saber se haveria a limitação de oportunidades educacionais de crianças e adolescentes residentes nas favelas cariocas, levando- 
se em conta a atuação de narcotraficantes nas favelas cariocas, o que poderia contribuir, de alguma maneira, para o quadro de segregação residencial de estudantes moradores de favelas, inclusive pela rede escolar, considerando a coação exercida por aqueles grupos, com imposição de regras limitadoras de locomoção às próprias populações daqueles espaços urbanos (SENTO SÉ; CANO; MARINHO, 2006).

Tal questão ganha relevo, considerando o advento das Unidades de Polícia Pacificadora (UPPs), na cidade do Rio de Janeiro, desde a instalação da primeira, na favela Santa Marta, em Botafogo, bairro da zona sul, em novembro de 2008, como alternativa ao modelo tradicional de intervenção policial, pautado em ações bélicas de repressão à criminalidade (BURGOS, 2011; CANO; BORGES; RIBEIRO, 2012).

E, como em algumas outras áreas da cidade do Rio de Janeiro, os bairros que compõem a chamada "Grande Tijuca" também receberam UPPs, a partir de junho de 2010, sendo que, para este trabalho, interessam aquelas instaladas nos complexos de "favelas", ou "comunidades", como Borel, Formiga, Macaco, Salgueiro e Turano.

Ainda que o narcotráfico, a violência urbana e a segurança pública não constituam focos específicos da pesquisa, reconheceu-se a necessidade de tomá-los como temas relacionados à desigualdade de oportunidades educacionais, considerando a possibilidade de uma política de segurança pública gerar efeitos sobre alguns aspectos educacionais, a partir de modelos de socialização em crianças e adolescentes (ELLEN; TURNER, 1997; JENCKS; MAYER, 1990), os quais, incorporando uma "sociabilidade violenta" (MACHADO DA SILVA, 2004) ou um "ethos guerreiro", típicos de facções de narcotraficantes (DOWDNEY, 2003; ZALUAR, 2007), rivalizariam no espaço escolar (GUIMARÃES, 2003; PENHA; FIGUEIREDO, 2009; ZALUAR; LEAL, 2001).

Se, por um lado, cabe grifar que as favelas não constituem únicos locais de violência urbana (VALLADARES, 2005), por outro, a hipótese inicial do estudo era que fatores como "sociabilidade violenta" e "ethos guerreiro" (ZALUAR; LEAL, 2001) poderiam inclusive ensejar uma seleção criteriosa dos alunos às escolas da cidade, por parte de gestores educacionais, preocupados em evitar possíveis conflitos intramuros (ALMEIDA; BORGES, 2005, p. A13).

Com base nesses pressupostos e a partir de uma hipótese de que a implementação das UPPs poderia ter alterado, em alguma medida, pelo próprio cunho "pacificador" de áreas tradicionalmente em conflito, o quadro de segregação residencial e, consequentemente, a geografia de oportunidades educacionais de estudantes oriundos de favelas, na cidade do Rio de Janeiro, a pesquisa vem sendo realizada à luz da questão norteadora de se saber como uma 
medida ligada à política governamental de segurança pública ou a um modelo específico de policiamento poderia gerar possíveis efeitos no campo da educação.

Assume-se, dessa forma, por intermédio de uma pesquisa qualitativa, realizada em 6 escolas da rede municipal do Rio de Janeiro, a busca de se compreender os possíveis efeitos das UPPs sobre as escolhas familiares e o sistema de matrícula de crianças e adolescentes, moradores de favelas localizadas na Grande Tijuca, pela própria rede municipal, tendo como referência a percepção dos funcionários das escolas selecionadas para esta pesquisa (diretores, coordenadores pedagógicos, professores e pessoal de apoio, composto, por exemplo, por agentes escolares, pessoal responsável pela limpeza e cozinha etc.) e de alunos de ambos os sexos, residentes em favelas da Grande Tijuca, distribuídos em duas turmas do $9^{\circ}$ ano do ensino fundamental, de uma das escolas visitadas.

No que diz respeito aos critérios de seleção das escolas, cabe registrar que há preferência àquelas que atendem tanto o primeiro segmento $\left(1^{\circ}\right.$ ao $5^{\circ}$ ano $)$ como o segundo segmento do ensino fundamental $\left(6^{\circ}\right.$ ao $9^{\circ}$ ano), que recebem alunos oriundos de favelas, considerando algumas escolas estarem localizadas no asfalto (Escola 1, Escola 2 e Escola 6), ao passo que outras situadas em favelas (Escola 3, Escola 4 e Escola 5) daquela região da cidade, sob influência de grupos rivais de narcotraficantes. Disso, resultou a seleção das Escolas 3 e 6, situadas em áreas de influência da Facção A, e das Escolas 1, 2, 4 e 5, localizadas em áreas sob a influência da Facção B.

Com relação aos funcionários, foram selecionados todos aqueles que pudessem contribuir com a pesquisa, num total de 37 entrevistados, mediante a coleta de suas respectivas percepções sobre as UPPs e se essas mesmas unidades poderiam ter efeitos sobre a vida escolar dos alunos moradores das favelas.

Até o presente momento, aos funcionários selecionados, têm sido aplicadas entrevistas semi-estruturadas, com um total de 40 questões, abordando temas ligados ao desempenho da função na escola (tempo de exercício, carga horária de trabalho, atribuição na escola, relação com os alunos etc.), cotidiano escolar (funcionamento da escola, relação com a comunidade, violência urbana, violência intramuros etc.), aos alunos (perfil dos alunos, relação com suas respectivas famílias, comportamento dos alunos, suas expectativas de vida etc.), tendo como pano de fundo das UPPs, sob o compromisso ético do pesquisador da manutenção do sigilo quanto aos nomes das escolas e às identidades dos entrevistados.

No que tange aos alunos, a seleção destes tem se dado no próprio curso da pesquisa, em consequência de se tentar captar suas percepções sobre seus cotidianos em suas residências e nas 
escolas em que estavam matriculados, inclusive em relação às UPPs, mediante um questionário aberto, contendo 30 perguntas, chegando-se a um total de 45 alunos matriculados em duas turmas do $9^{\circ}$ ano do ensino fundamental de uma das escolas selecionadas para a pesquisa (Escola 6).

A pesquisa de campo foi realizada, num primeiro instante, nos anos de 2014 e 2015, por ocasião do doutorado em educação pela UFRJ - e que culminou com uma tese publicada (SEGAL, 2015) - e retomada, num segundo momento, no ano de 2019, seguindo os mesmos métodos da pesquisa adotados anteriormente.

A justificativa dessa mesma pesquisa está na tentativa de se compreender uma possível variação nas percepções dos funcionários das escolas municipais do Rio de Janeiro, situadas na Grande Tijuca, desde a instalação das UPPs e neste momento de "crise" na área de segurança pública com impactos sobre a manutenção ou não de tais unidades policiais (CORRÊA, 2019; MEROLA, 2017).

E, no que se refere à sua relevância, pretende-seque a pesquisa proporcione dados suficientes para aqueles que desejam realizar estudos sobre os efeitos esperados, ou não, de uma medida associada à segurança pública em face de alguns aspectos educacionais, como aqueles que dizem respeito à restrição de oportunidades educacionais de estudantes moradores de favelas, como aquelas localizadas na cidade do Rio de Janeiro.

\section{A “cultura da evitação"como fator de desigualdade das oportunidades educacionais}

Desde o início, importa saber se a implementação das UPPs teria impactado na vida de estudantes moradores de favelas, com foco territorial na região da cidade do Rio de Janeiro conhecida como Grande Tijuca, considerando dados de pesquisas que apontam para o protagonismo dos narcotraficantes no cotidiano das favelas cariocas (DOWDNEY, 2003) e na publicação de uma série jornalística que traz à tona a influência dos narcotraficantes na rotina das escolas públicas da mesma cidade (ALMEIDA; BORGES, 2005), reproduzindo-se assim uma "sociabilidade violenta" entre jovens em idade escolar (MACHADO DA SILVA, 2004; ZALUAR; LEAL, 2001) e restringindo o direito de locomoção das populações residentes nas favelas.

Inicialmente, durante as entrevistas, foi possível coletar dados (diretor da Escola 1, diretor adjunto da Escola 4, professor e agente educador da Escola 6) que sugerem que a seleção das escolas, por parte das famílias, ainda tem se dado em razão da proximidade de seus respectivos 
lares, na esteira de dados de outros estudos (ALVES; FRANCO JÚNIOR, RIBEIRO, 2008; ZUCCARELLI; CID, 2010), o que foi reforçado por 12alunos entrevistados (Escola 6), ao longo da pesquisa de campo, como fator determinante na escolha de suas famílias sobre os estabelecimentos em que os mesmos haveriam de estudar.

Além disso, existem outros fatores atribuídos para que as famílias selecionem os estabelecimentos em que seus filhos são matriculados diz respeito ao prestígio escolar (diretor e diretor adjunto da Escola 1; diretor e coordenador pedagógico da Escola 3; e um professor da Escola 6)e às relações de vizinhança (diretor da Escola 1, o diretor e o coordenador pedagógico da Escola 3), o que vai ao encontro dos estudos anteriores sobre o assunto (COSTA; KOSLINSKI, 2011; COSTA; PRADO; ROSISTOLATO, 2013).

Entretanto, o leque de percepções dos profissionais ouvidos (diretor da Escola 3, coordenador pedagógico da Escola 3, diretor da Escola 4, diretor adjunto da Escola 4, e diretor da Escola 5), acerca seleção das escolas, por parte das famílias, se amplia, quando a atuação dos narcotraficantes surge como outro fator a ser considerado na redução das geografias subjetivas de oportunidades educacionais de jovens moradores de favelas, se coadunando ao discurso dos alunos (da Escola 6) moradores de favelas (Favelas 2, 3 e 4), dominadas pela Facção B, de que eles não estudariam em escolas próximas ou dentro de favelas controladas pela Facção A. Pois, a resposta de 41 alunos foi negativa, entre 45 participantes, tendo em vista o risco alegado sobre suas próprias integridades físicas, reafirmando a existência de "fronteiras invisíveis" (FRIDMAN, 2008; SMALL, 2004).

E, com o intuito de confirmar ou refutar as respostas dos alunos, aos funcionários das escolas, foi perguntado se a implantação das UPPs teria alterado as escolhas familiares das escolas e as vidas cotidianas dos jovens moradores de favelas, considerando as limitações territoriais supostamente impostas pelo narcotráfico na região da Grande Tijuca. As respostas dos funcionários (diretores das 6 escolas selecionadas na pesquisa, 2 coordenadores pedagógicos) foi negativa. $\mathrm{Na}$ percepção desses entrevistados, não houve qualquer mudança na "cultura de evitação" (SILVA; MILITO, 1995), mesmo com a presença das UPPs nas favelas, inclusive nas escolas da rede municipal.

Desse modo, foi possível, assim, compreender como as "fronteiras invisíveis" entre os diversos espaços urbanos, inclusive entre as favelas, ainda impõem experiências forçadas de “confinamento social” (MACHADO DA SILVA, 2004).

Mas, se por um lado, há dados que sugerem a existência de critérios restritivos acerca da seleção das escolas, por parte das famílias, e de isolamento entre os alunos, por outro, cabia 
perguntar se o órgão municipal competente e/ou as escolas efetuariam alguma segregação aos alunos moradores de favelas, tendo em vista suas origens residenciais.

\section{$2 \mathrm{O}$ "ethos guerreiro" como outro fator de desigualdade das oportunidades educacionais}

Ainda nas mesmas escolas, foi perguntando se havia matrícula de estudantes com base em suas origens residenciais, considerando a relação desse aspecto com as limitações territoriais impostas por grupos de narcotraficantes, o que, aliás, poderia revelar um quadro de segregação residencial, pela rede municipal ou pelas direções das escolas pesquisadas, para além das questões envolvendo prestígio escolar, alta demanda das famílias em relação às vagas nas instituições de ensino, proximidade residencial entre os lares e as escolas etc. (ALVES; FRANCO JUNIOR; RIBEIRO, 2008; COSTA; KOSLINSKI, 2011). A resposta para todos os casos foi negativa.

Em 2 escolas municipais (Escola 1 e Escola 4), foi dito por seus funcionários que não haveria restrição quanto à matrícula de alunos oriundos de favelas controladas por grupos rivais de narcotraficantes. Entretanto, segundo esses mesmos funcionários, haveria a recomendação para que as famílias procurassem escolas próximas às suas residências ou que os alunos residentes naqueles territórios não revelassem seus respectivos endereços, com o intuito de preservar suas integridades físicas (diretor adjunto da Escola 1 e diretor adjunto da Escola 4), eis que existe a preocupação entre os gestores escolares com possíveis conflitos violentos entre estudantes provenientes de diferentes favelas, dominadas por facções rivais de narcotraficantes, estando em jogo a manutenção de um "bom clima" nas escolas (CUNHA, 2011), evitando-se assim que os conflitos extramuros sejam reproduzidos no ambiente escolar (PENHA; FIGUEIREDO, 2006).

Tais depoimentos possibilitam uma explicação sobre o comportamento dos jovens moradores de favelas, matriculados nas escolas pesquisadas com fundamento na ideia de efeitovizinhança sobre modelos de comportamento juvenil (ALVES; FRANCO JUNIOR; RIBEIRO, 2008; ELLEN; TURNER, 1997; JENCKS; MAYER, 1990), considerando suas atitudes e o contexto em que residem. As teorias de "homem como fruto do meio", orientado pela sociedade em que os indivíduos vivem (DURKHEIM, 2007) e "orientado pela ação dos outros indivíduos" (WEBER, 1999) foram confirmadas pelas percepções de alguns entrevistados (coordenador pedagógico da Escola 1; agente de limpeza da Escola 3; diretor principal da Escola 5).

Tanto que um elemento marcante atribuído à sociabilidade entre os jovens moradores de favelas, matriculados nas escolas pesquisadas, a partir da percepção dos entrevistados, diz respeito ao chamado "ethos guerreiro" (ELIAS, 1997) e aos impactos da violência urbana sobre a 
rotina das escolas (PENHA; FIGUEIREDO, 2006), inclusive mediante ameaças e/ou agressões entre os alunos (GUIMARÃES, 2003; ZALUAR; LEAL, 2001).

Jovens residentes em uma dada favela percebem em outros jovens, moradores de outras favelas, controladas por um grupo rival de narcotraficantes, a figura do "alemão", que, no jargão desses mesmos grupos, significa "inimigo" (DOWDNEY, 2003), reforçando as "fronteiras invisíveis" (FRIDMAN, 2008) entre as populações das favelas, inclusive, entre os mais jovens. E, em vista disso, qualquer possibilidade de interação com o "outro" é rechaçada, sob a "força do coletivo" (ELIAS; SCOTSON, 2000), podendo implicar, inclusive, na reprovação, na punição, e até na exclusão daquele que viole as normas do grupo ao qual pertence.

Tem-se, pois, uma situação que iria além de uma dualidade "asfalto x favela", produto de uma aparente segregação urbana, mediante uma dualidade "favela x favela", fruto da segregação entre as populações jovens residentes nesses territórios (MOYSÉS, 2001), que parece persistir, mesmo em tempos de UPPs, mediante o uso de linguagens simbólicas de demarcação espacial, que se vale de pichações cantorias de funks, inclusive em alusão a determinados grupos de narcotraficantes (GUIMARÃES, 2003).

Todavia, se, por um lado, a implementação das UPPs não teria causado o fim das atividades dos narcotraficantes, segundo percepções captadas nas entrevistas, por outro, existem relatos de funcionários das escolas que apontam para o fim do ingresso de pessoas estranhas àqueles estabelecimentos, inclusive em comportamento (tático ou expressamente) ameaçador e para um arrefecimento do "ethos guerreiro" entre os alunos das séries iniciais do ensino fundamental das escolas (diretor e agente educador da Escola 1; diretor, professor e agente de limpeza da Escola 3; diretor da Escola 4; diretor e agente educador da Escola 5; diretor e professor da Escola 6).

Nas percepções dessas pessoas, tais fatos teriam deixado os alunos do primeiro segmento do ensino fundamental ( $1^{\circ}$ ao $5^{\circ}$ ano) "mais calmos", "menos estressados", fazendo com que seus comportamentos violentos se modificassem, com um aparente distanciamento da referência dos narcotraficantes como figuras centrais no cotidiano de suas respectivas vidas.

Sobre os alunos matriculados no segundo segmento do ensino fundamental $\left(6^{\circ}\right.$ ao $9^{\circ}$ ano), com faixa etária entre 11 e 15 anos, tais efeitos positivos ainda não teriam sido sentidos. Isso porque, no relato dos mesmos entrevistados, como aqueles já teriam experimentado, por um considerável tempo, ambientes de extrema violência (tiroteios, linchamentos e execuções públicas, corpos expostos nas favelas), ainda seria difícil distanciá-los de um modelo de comportamento baseado na sociabilidade violenta. 
Contudo, nas entrevistas realizadas com alguns funcionários, que ainda permanecem em atividade em algumas escolas selecionadas para a pesquisa (diretores das Escolas 5 e 6, professores da escola 3 e 5), percebe-se a persistência do "ethos guerreiro" inclusive entre aqueles alunos que outrora se encontravam matriculados nas turmas do primeiro segmento do ensino fundamental ( $1^{\circ}$ ao $5^{\circ}$ ano) das escolas municipais, em consequência da "crise na segurança pública e das próprias UPPs", haja vista o recrudescimento dos confrontos armados entre policiais e narcotraficantes e entre grupos rivais de narcotraficantes. A aparente calma entre esses alunos deu lugar a comportamentos violentos e identificados com os grupos de narcotraficantes (gestos, falas, canções e pichações).

Se nas entrevistas realizadas com os funcionários das escolas selecionadas, no período 2014-2015, havia um sentimento de ambiguidade em relação ao futuro das UPPs, nas entrevistas efetuadas no primeiro trimestre ano de 2019, o sentimento captado é de resignação quanto ao seu suposto fracasso. Afinal, para alguns entrevistados "nada mudou” (professor da Escola 3) ou “voltamos à estaca zero" (professor da Escola 5).

\section{Conclusão}

Falar em desigualdades de oportunidades educacionais, inclusive quando se toma a cidade Rio de Janeiro como referência de análise, implica em considerar fatores como a contraposição entre a elevada demanda e as limitadas ofertas de vagas nas escolas da rede municipal, a origem residencial dos candidatos e os critérios, nem sempre claros, para as matrículas, o que abre brecha para a uma intervenção discricionária por parte da rede educacional ou das direções dos estabelecimentos de ensino, privilegiando pessoas em detrimento de outras.

Com isso, vê-se uma contraposição entre a geografia objetiva de oportunidades educacionais, tendo em vista um vasto número de escolas postas à disposição dos interessados, e a geografia subjetiva de oportunidades educacionais, considerando a percepção das famílias de que o acesso não está igualmente franqueado em todas as escolas da rede municipal.

No entanto, há também a percepção de "fronteiras invisíveis" impostas por grupos de narcotraficantes como elemento que têm dificultado o acesso das famílias moradoras de favelas às escolas da rede municipal, com a restrição das oportunidades educacionais, pois, onde impera a "cultura do silêncio" e a "cultura do medo", entre as famílias, a escolha das escolas ocorre de acordo com o grupo ou facção de narcotraficante que vem exercendo influência em determinadas áreas da cidade. Tal fator parece impor, aliás, outra forma de isolamento das populações, para 
além da dualidade "asfalto x favela", portanto, também de uma dualidade "favela x favela", de acordo com a percepção de funcionários (diretores, coordenadores, professores e pessoal de apoio) de escolas municipais localizadas na região da Grande Tijuca, bem como na percepção de estudantes moradores de favelas matriculados nessas mesmas escolas, naquela região da cidade do Rio de Janeiro.

Mas também há dados que sugerem a incorporação do "ethos guerreiro" dos narcotraficantes, por parte de um contingente de estudantes, ainda que não haja envolvimento direto destes últimos com aqueles grupos. Comportamentos agressivos, pichações e canções em alusão às facções de narcotraficantes têm sido as marcas de uma territorialidade entre os estudantes das escolas municipais do Rio de Janeiro, que é levada em consideração tanto pelas famílias, no momento de selecionar as escolas para seus filhos, como pelo próprio poder público quando aloca os alunos oriundos de favelas nos próprios estabelecimentos de ensino da rede, com o objetivo de que a violência urbana seja reproduzida intramuros, restringindo-lhes ainda mais a geografia de oportunidades educacionais.

Pois, à guisa de uma conclusão, pode-se perceber que as UPPs ainda não tiveram qualquer efeito preponderante sobre o quadro de desigualdade de oportunidades educacionais de estudantes moradores de favela na cidade do Rio de Janeiro, diante das "fronteiras invisíveis" e da "cultura de evitação".

\section{Referências}

ALMEIDA, Gustavo; BORGES, Waleska. Um futuro sem grades: especialistas debatem tema de série do 'JB' e Ministério da Educação investe contra violência nas escolas. Jornal do Brasil, Rio de Janeiro, p. A26, 12 jun. 2005.

ALMEIDA, Gustavo; BORGES, Waleska. Cidade dividida até nos pátios: crise em conselhos tutelares deixa à mostra influência das facções sobre pais na escolha do colégio dos filhos. Jornal do Brasil, Rio de Janeiro, p. A13, 11 jun. 2005.

ALMEIDA, Gustavo; BORGES, Waleska. Professores vivem na fronteira do medo: sindicato já registrou agressões de pais de alunos e ameaças de adolescentes. Jornal do Brasil, Rio de Janeiro, p. A15, 10 jun. 2005.

ALMEIDA, Gustavo; BORGES, Waleska. Violência nas escolas prejudica 120 mil: documento reservado de reunião revela que prefeitura já trabalhava no problema. Jornal do Brasil, Rio de Janeiro, p. A17, 09 jun. 2005.

ALMEIDA, Gustavo; BORGES, Waleska. Filhos de policiais na linha de fogo: traficantes já invadiram direção de escolas duas vezes para tentar descobrir que alunos teriam parentesco com agentes da lei. Jornal do Brasil, Rio de Janeiro, p. A17, 8 jun. 2005. 
ALMEIDA, Gustavo; BORGES, Waleska. Sem segurança nos corredores: déficit e inspetores nas escolas abre caminho para aliciamento e envolvimento de alunos com o tráfico de drogas. Jornal do Brasil, Rio de Janeiro, p. A14, 07 jun. 2005.

ALMEIDA, Gustavo; BORGES, Waleska. A cartilha da violência: professores recebem ameaças e ordens do tráfico do tráfico; e Jovens reproduzem em sala de aula o cotidiano violento do morro. Jornal do Brasil, Rio de Janeiro, p. A13, 06 jun. 2005.

ALMEIDA, Gustavo; BORGES, Waleska. Adaptar para sobreviver: escolas criam novas regras de convivência com comunidades carentes para evitar riscos; e autoridades minimizam. Jornal do Brasil, Rio de Janeiro, p. A26, 05 jun. 2005.

ALMEIDA, Gustavo; BORGES, Waleska. Lições do medo: alunos de escolas do Rio, identificados com siglas do tráfico, aumentam situação de risco dos professores e colocam Educação em risco. Jornal do Brasil, Rio de Janeiro, p. A25, 05 jun. 2005.

ALVES, Fátima; FRANCO JUNIOR, Francisco Creso Junqueira.; RIBEIRO, Luiz César de Queiroz. Segregação residencial e desigualdade escolar no Rio de Janeiro. In: RIBEIRO, Luiz César de Queiroz; KAZTMAN, Ruben. (Org.). A cidade contra a escola?: segregação urbana e desigualdades educacionais em grande cidades da América Latina. Rio de Janeiro: Letra Capital, FAPERJ; Montevidéu, Uruguai, IPPES, 2008, p. 91-118.

BRITO, Márcia Terra de Souza; COSTA, Márcio. Práticas e percep̧ões docentes e suas relações com o prestígio e clima escolar das escolas públicas do município do Rio de Janeiro. Revista Brasileira de Educação, v. 15, n. 45, set./dez. 2010, p. 500-594. Disponível em:

<http://www.scielo.br/pdf/rbedu/v15n45/08.pdf>. Acesso em: 08 abr. 2012.

BRUEL, Ana Lorena. Distribuição de oportunidades educacionais: o programa de escolha de escola pela família da rede municipal do Rio de Janeiro. 2014. 202f. Tese (Doutorado em Educação). Faculdade de Educação, Universidade Federal do Rio de Janeiro, 2014. Disponível em: <https://ppge.educacao.ufrj.br/Teses2014/tanalorena.pdf>. Acesso em: 08 jun. 2019.

BURGOS, Marcelo Baumann et al. O efeito UPP na percep̧̧ão dos moradores das favelas. Desigualdade \& Diversidade, Revista de Ciências Sociais, Rio de Janeiro: PUC-Rio, nº 11, p. 49-98, ago./dez. 2011. Disponível em: <http://desigualdadediversidade.soc.puc-rio.br/media/4artigo11.pdf> . Acesso em: 12 dez. 2013.

CANO, Ignacio; BORGES, Doriam; RIBEIRO, Eduardo. Os donos do morro: uma avaliação exploratória dos impactos das unidades de polícia pacificadoras (UPP) no Rio de Janeiro. São Paulo: Fórum de Segurança Pública; LAV/UERJ, 2012.

CHRISTOVÃO, Ana Carolina; SANTOS, Maria Milão dos. A escola na favela ou a favela na escola? In: RIBEIRO, Luiz César de Queiroz et al. (Org.). Desigualdades urbanas, desigualdades escolares. Rio de Janeiro: Letra Capital; Observatório das Metrópoles; IPPUR/UFRJ, 2010, p. 277297.

CORRÊA, Douglas. Alerj aprova em primeira discussão projeto que prevê fim das UPPs. EBC, Agência Brasil, Política, 19/02/2019. Disponível em: <http://agenciabrasil.ebc.com.br/politica/noticia/2019-02/alerj-aprova-em-primeira-discussaoprojeto-que-preve-fim-das-upps $>$. Acesso em: 10 mar. 2019. 
COSTA Márcio da; KOSLINSKI, Mariane Campelo. Quase-mercado oculto: disputa por escolas "comuns" no Rio de Janeiro. Cadernos de Pesquisa, v. 41, n. 42, p. 247-266, jan./abr. 2011. Disponível em: <http://www.scielo.br/pdf/cp/v41n142/v41n142a13.pdf>. Acesso em: 10 nov. 2012.

COSTA, Márcio da; PRADO, Ana Pires do; ROSISTOLATO, Rodrigo. Talvez se eu tivesse algum conhecimento...: caminhos possíveis em um sistema educacional público e estratificado. Interseções, Rio de Janeiro, v. 14, p. 165-193, 2013. Disponível em:

$<$ http://www.epublicacoes.uerj.br/index.php/intersecoes/article/viewFile/5773/4193>. Acesso em: 02 fev. 2014.

CUNHA, Marcela Brandão. Possiveis relações entre violência dos alunos, clima escolar e eficácia coletiva. Educação e Pesquisa, São Paulo, v. 40, n. 4, p. 1077-1092, out./dez. 2014. Disponível em: <http://www.scielo.br/pdf/ep/v40n4/aop1252.pdf>. Acesso em: 18 jun. 2015.

DOWDNEY, Luke. Crianças do tráfico: um estudo de caso de crianças em violência armada organizada no Rio de Janeiro. Rio de Janeiro: 7 Letras, 2003.

DURKHEIM, Émile. As regras do método sociológico. [Trad.] Paulo Neves. 3. Ed. São Paulo: Martins Fontes, 2007.

ELIAS, Norbert. Os alemães: a luta pelo poder e a evolução do habitus nos séculos XIX e XX. [Trad.] Álvaro Cabral. Rio de Janeiro: Jorge Zahar Editor, 1997.

ELIAS, Norbert; SCOTSON, John L. Os estabelecidos e os outsiders. [Trad.] Vera Ribeiro. Rio de Janeiro: Jorge Zahar Editor, 2000.

ELLEN, Ingrid Gould; TURNER, Margery Austin. Does neighborhood matter?: assessing recent evidence. Housing Policy Debate, vol. 8, iss. 4, p. 833-866, 1997. Disponível em:

$<$ http://content.knowledgeplex.org/kp2/kp/text_document_summary/scholarly_article/relfiles /hpd_0804_ellen.pdf $>$. Acesso em: 04 ago. 2012.

FLORES, Carolina. Segregação residencial e resultados educacionais na cidade de Santiago do Chile. In: RIBEIRO, Luiz César de Queiroz; KAZTAMN, Ruben (Org.). A cidade contra a escola?: segregação urbana e desigualdades educacionais em grande cidades da América Latina. Rio de Janeiro: Letra Capital, FAPERJ; Montevidéu, Uruguai, IPPES, 2008, p. 145-179.

FRIDMAN, Luis Carlos. Morte e vida favelada. In: MACHADO DA SILVA, Luis Antonio (Org.). Vida sob cerco: violência e rotina nas favelas do Rio de Janeiro. Rio de Janeiro: Nova Fronteira, 2008, p. 77-98.

GUIMARÃES, Eloísa. Escola, galera e narcotráfico. 2. Ed. Rio de Janeiro: UFRJ, 2003.

JENCKS, Christopher; MAYER, Susan E. Residential segregation, job proximity and black job opportunities: the empirical status of the spatial mismatch hypotesis. In: LYNN, Laurence E..; McGEARY, Michael G. H. (Ed.). Inner-city poverty in the United States. Washington, DC: National Academy of Science Press, 1990, p. 187-288. Disponível em:

<http:/ /www.nap.edu/openbook.php?record_id=1539\&page=187>. Acesso em: 28 set. 2012. 
MACHADO DA SILVA, Luis Antonio. Sociabilidade violenta: por uma interpretação da criminalidade contemporânea no Brasil urbano. Sociedade e Estado, v. 19, n. 1, p. 53-84, jan./jun. 2004. Disponível em: <http://www.scielo.br/pdf/se/v19n1/v19n1a04.pdf>. Acesso em: 10 nov. 2012.

MEROLA, Ediane. 'Reage, Rio!': sociólogo diz que crise na segurança só acaba se cenário político do estado mudar. O Globo, Rio de Janeiro, 06/12/2017. Disponível em:

$<$ https://oglobo.globo.com/rio/reage-rio-sociologo-diz-que-crise-na-seguranca-so-acaba-secenario-politico-do-estado-mudar-22158613>. Acesso em: 28 mar. 2019.

MOYSÉS, Aristides. A produção de territórios segregados na Região Noroeste de Goiânia: uma leitura sócio-política. In: II Encontro Democracia, Igualdade e Qualidade de Vida: desafios para as cidades no século XXI, 7 a 9/10/2001, Belém. Disponível em: <http://www.observatoriodasmetropoles.ufrj.br/download/arimoyses_tersegreg.pdf $>$. Acesso em: 16 mar. 2014.

PENHA, Ana Cláudia de Souza; FIGUEIREDO, Maria das Dores. O impacto do tráfico de drogas na rotina escolar. In: ZALUAR, Alba; ALVITO, Marcos (Org.). Um século de favela. 5. Ed. Rio de Janeiro: FGV, 2006, p. 265-280.

SEGAL, Robert Lee. Unidades de polícia pacificadora (UPPs) e escolas: UPPs e aspectos educacionais no Rio de Janeiro - o caso das escolas na grande Tijuca. Rio de Janeiro: Letra Capital, 2015. Disponível em: $<$ http://media.wix.com/ugd/22bbaa_3c0bf9e80b444d5c9a05fd35c23f8b59.pdf >. Acesso em: 20 mar. 2019.

SENTO SÉ, João Trajano; CANO, Ignacio; MARINHO, Andrea. Efeitos humanitários dos conflitos entre facções do tráfico de drogas numa comunidade do Rio de Janeiro. Rio de Janeiro: UERJ/LAV, 2006. Disponível em: < http://www.lav.uerj.br/docs/rel/2006/fac_rocinha_rio_2006.pdf>. Acesso em: 24 jan. 2015.

SILVA, Hélio Raimundo Santos; MILITO, Cláudia. Vozes do meio fio. Rio de Janeiro: RelumeDumará, 1995.

SMALL, Mario Luis. Villa Victoria: the transformation of social capital in a Boston barrio. Chicago: University of Chicago Press, 2004.

VALLADARES, Lícia do Prado. Do mito de origem à favela.com. Rio de Janeiro: FGV, 2005.

WEBER, Max. Economia e sociedade: fundamentos da sociologia compreensiva. Vol. I. [Trad.] Regis Barbosa e Karen Elsabe Barbosa. Brasília: UnB, 1999.

ZALUAR, Alba. Integração perversa: pobreza e tráfico de drogas. Rio de Janeiro: FGV, 2007.

ZALUAR, Alba; LEAL, Maria Cristina. Violência extra e intramuros. Revista Brasileira de Ciências Sociais, v. 16, n. 45, p. 145-164, Fev./2001. Disponível em:

<http://www.scielo.br/pdf/rbcsoc/v16n45/4335.pdf>. Acesso em: 11 jun. 2011.

ZUCCARELLI, Carolina; CID, Gabriel. Oportunidades educacionais e escolhas familiares no Rio de Janeiro. In: RIBEIRO, Luiz César de Queiroz et al. (Org.). Desigualdades urbanas, 


\section{Dialogia}

SEGAL, Robert Lee. Sobre escolas, unidades de polícia pacificadora (UPPs) e desigualdades de oportunidades educacionais na cidade do Rio

desigualdades escolares. Rio de Janeiro: Letra Capital; Observatório das Metrópoles; IPPUR/UFRJ, 2010, p. 249-276.

Recebido em: 22 maio 2019 / Aprovado em: 25 jun. 2019

\section{Cite como}

SEGAL, Robert Lee. Sobre escolas, unidades de polícia pacificadora (UPPs) e desigualdades de oportunidades educacionais na cidade do Rio de Janeiro. Dialogia, São Paulo, n. 32, p. 278-291, maio/ago. 2019. Disponível em: https://doi.org/10.5585/Dialogia.n32.13954. 